\title{
Plivanje u triatlonu
}

\author{
Silvia Race \\ Sandra Vujkov \\ Visoka strukovna škola za obrazovanje vaspitača i trenera, Subotica
}

\begin{abstract}
Triathlon is an Olympic sport that consists of three cyclic events: swimming, running and cycling, which are taking place one after another. Triathlon race begins with swimming, mainly on open water. Even the great sport experts analyze triathlon through each segmental technique. In regards to that, triathlon-swimming technique is not identical to the classic technique in swimmers; moreover, there are significant differences in certain elements. The first triathlon competition was held in 1977 in Hawaii, organized by a group of US Marines. The aim of this paper was to explain the way of training, tactical preparation and other relevant elements related to the swimming part of the triathlon race.
\end{abstract}

Keywords: triathlon, swimming, marathon swimming, preparation
Sažetak: Triatlon je olimpijski sport koji se sastoji od tri ciklične takmičarske discipline: plivanja, trčanja i biciklizma, koje se odvijaju jedna za drugom. Triatlonska trka započinje plivanjem, uglavnom na otvorenim vodama. Čak i veliki stručnjaci iz ostalih sportova posmatraju triatlon kroz svaku tehniku posebno, međutim, ono što je specifično jeste da plivačka triatlon tehnika nije poptuno ista kao klasična tehnika kod plivača, štaviše postoje značajne razlike $u$ određenim elementima. Prvo triatlonsko takmičenje je održano 1977. godine na Havajima u organizaciji grupe američkih marinaca. Cilj ovog rada je da pojasni način treniranja, taktiku pripreme $\mathrm{i}$ ostale relevantne elemente $\mathrm{u}$ vezi sa plivačkim delom triatlonske trke.

Ključne reči: triathlon, plivanje, maratonsko plivanje, priprema

Rad je primljen 18.05.2016.

Odobren 23.05.2016.

Kontakt podaci:

Silvia Race

Visoka škola strukovnih studija za obrazovanje vaspitača i trenera

Subotica, Banijska 67,

Tel: +38124547870

E-mail: silviarace@yahoo.com 


\section{Uvod}

Trenažni proces sportiste je kompleksan proces i složena simbioza više različitih elemenata koji se praktikuju kroz stalno vežbanje, koje aktivira fiziološke procese superkompenzacije i adaptacije organizma. Posledica takvog vežbanja jeste poboljšanje fizičkih, motoričkih, tehničkih, taktičkih, psihičkih i drugih elemenata kod sportista. Svi navedeni elementi se moraju praktikovati kao celina, jer su međusobno povezani na način koji utiče na performanse sportiste. Postoji tesna veza među svim vrstama priprema sportista na kojima se mora paralelno raditi, gde se u svakom periodu treninga stavlja akcenat na jednu ili više vrsta, kako bi se performanse sportiste razvijale na najefikasniji i najekonomičniji način. Tehnika se definiše kao skup metoda i procesa koji se primenjuju u nekom radu (Klajn, Šipka, 2006). Tehnika se često definiše i kao forma, odnosno, stil kretanja, pri čemu se pod formom podrazumeva struktura kretanja, odnosno, vežbi. Između forme i tehnike kretanja postoji razlika. Tehniku kretanja koja je nastala u toku višegodišnjeg treninga, sačinjava specijalna forma kretanja, koja je usmerena prema cilju najefikasnijeg delovanja u pokretu. Taktika se definiše kao unapred dobro osmišljen i pripremljen plan aktivnosti koji omogućava uspešno korišćenje individualnih, grupnih ili kolektivnih sposobnosti i osobina. Postoje sprint triathlon, olimpijski triathlon $\mathrm{i}$ Iron man. $\mathrm{U}$ svakom od njih plivaju se različite distance. Ovaj rad će objasniti način treniranja, taktike i sve ostalo što je važno da se zna u vezi plivačkog dela triatlonske trke.

\section{Istorijat}

Prvo svetsko prvenstvo na olimpijskoj distanci je održano 1989. godine u Avinjonu i učestvovalo je čak 800 takmičara u svim starosnim kategorijama. Od 1996. održavaju se kvalifikacije za svetsko prvenstvo u elitnoj kategoriji. Danas na svetskom prvenstvu u eliti nastupa stotinak takmičara, a u tzv. age kategoriji vise od 1000.

Ironman na Havajima smatra se nezvaničnim prvenstvom sveta. 1990. godine održana je prva Ironman serija i pobednik je bio Scot Tinli. Iz godine u godinu broj takmičara se povećavao, a takođe i broj takmičenja. Širom sveta su osnivani nacionalni savezi da bi 1989. godine bila osnovana Svetska triatlonska unija (ITU) na inicijativu MOK-a.

Triatlon je od 2000. godine uvršten u olimpijske sportove i ženska triatlonska trka je imala čast da bude prvo takmičenje na Olimpijskim igrama u Sidneju.

\section{Vrste triatlona}

Triatlonska takmičenja se održavaju na različitim distancama. Takozvana "short" distanca je $1500 \mathrm{~m}$ plivanja, $40 \mathrm{~km}$ voznje bicikla i $10 \mathrm{~km}$ trčanja. Ova distanca se još zove i olimpijska, zbog toga što je to standardna kvalifikaciona distanca za olimpijske igre, i naravno distanca na kojoj se triatlonci takmiče na olimpijskim igrama.

Pored olimpijskog, populan je tzv. "sprint triatlon", koji se održava na duplo kraćoj distanci koja iznosi $750 \mathrm{~m}$ plivanja, $20 \mathrm{~km}$ vožnje bicikla i $5 \mathrm{~km}$ trčanja. U sprintu se obično takmiče mlađe kategorije, tj. juniori i pioniri.

Kod nas su takmičenja na ovoj distanci dosta zastupljena, pošto je teško obezbediti sredstva za olimpijski triatlon.

Vrhunac i želja svakog triatlonca je da nastupi na najtežoj distance, a možda i najtežem sportu na svetu, a to je Ironman (čovek od čelka). Ironman se održava na distancama od $3800 \mathrm{~m}$ plivanja, $180 \mathrm{~km}$ vožnje bicikla i $42 \mathrm{~km}$ trčanja (maraton). Najpopularniji je svakako havajski Ironman, koji je ujedno i svetsko prvenstvo na ovoj distanci. Za ovu, kao i za druge Long distance trke (zajedničko ime za sve triatlone koji su duži od olimpijskog) je to sto u biciklističkom segmentu takmičar ne sme da se draftuje, tj. zabranjena je vožnja u grupi, koja je značajno lakša od solo vožnje.

U našoj zemlji se ne održavaju Ironman trke, ali možemo da se pohvalimo da imamo takmičare koji se takmiče u Ironman distanci. To su Bojan Marić, koji ima i najbolji rezultat u zemlji, Aleksandar Bzdusok i Vero Janoš koji je nas prvi takmičar u Ironman distanci .

Pošto je triatlon letnji sport i zahteva lepo vreme i nije ga moguće održati u zimskom periodu

(naravno mislim na zemlje u kojima je zima hladna), stvoren je zimski triatlon. Zimski triatlon se sastoji iz trčanja na skijama, vožnje planinskog bicikla i trčanja. Distance na kojim se takmiče zimski triatlonci su 20-40-10. Od naših takmičara se $\mathrm{u}$ zimskom triatlonu takmiči Aleksandar Milenković koji je 2000. ostvario značajne rezultate u svetskom i evropskom kupu.

Postoje i razne druge varijacije triatlonskih takmičenja, kao što su neki ultrakratki za decu i rekreativce i neki dugi, kao što je half Ironman, ali tu ne postoje standardi, pa ih nećemo detaljnije opisivati. 


\section{Takmičarska pravila}

Plivanje: za vreme plivanja takmičar je dužan da pliva po označenoj stazi i svako skretanje sa staze u smislu skraćivanja distance se kažnjava diskvalifikacijom.

Takmičar u toku plivačkog segmenta ne sme da koristi nikakva pomagala (peraja, lopatice, itd), jer će u protivnom biti diskvalifikovan. Mogu se koristiti naočare za plivanje i kapa. Može se koristit i odelo za plivanje, neoprensko, debljine do 5mm, ukoliko je dozvoljeno od strane organizatora, tj. ako je temperatura vode ispod $20^{\circ} \mathrm{C}$ za olimpijski triatlon, dok je za Ironman ta granica na $24^{\circ} \mathrm{C}$.

Bicikl: što se tiče biciklističkog segmenta od obavezne opreme potreban je bicikl, dres, takmičarski broj i kaciga. Pravila Svetske triatlonske unije (ITU) propisuju i neke pojedinosti koje se tiču samog bicikla. Ta pravila se odnose na: kočnice-moraju biti ispravne i ne smeju imati lufta; volan mora biti klasičan; aerobar ne sme prelaziti najistureniju tačku ručica kočnica, a sve zajedno ne sme da prelazi osovinu prednjeg točka za vise od $15 \mathrm{~cm}$, točkovi moraju biti iste veličine, ram mora biti u osnovi trugao, cevi ne smeju biti savijene i nepravilnog preseka i horizontalna i vertikalna cev moraju biti zavarane na vratu rama, prečnik cevi ne sme biti veći od 8 $\mathrm{cm}$. Ukoliko organizator naglasi da se primenjuju ITU pravila, takmičaru čiji bicikl ne zadovoljava ove uslove, neće biti dozvoljeno da isti koristi na trci.

Što se tiče draftinga (vožnje u zavetrini iza drugog takmičara), nije dozvoljen između muškaraca i žena i nije dozvoljen uopšte na long distace takmičenjima. Pod zonom drafta se podrazumeva prostor $\mathrm{u}$ širini od po $1,5 \mathrm{~m}$ bočno od bicikla sa leve i desne strane i prostor $10 \mathrm{~m}$ iza bicikla mereno od najisturenije prednje tačke na biciklu. Čim jedan takmičar pređe drugog za polovinu obima prednjeg točka, smatra se da ga je prestigao, te se ovaj mora povući i pridržavati pravila o draftingu.

Trčanje je poslednja disciplina. Na trčanju je obavezno da takmičar prati označenu stazu i kao i u prethodna dva segmenta ne sme da skreće sa staze u smislu njenog skraćivanja. Ukoliko napusti stazu može se vratiti na nju samo na mestu na kojem ju je napustio. Hodanje je dozvoljeno. Od opreme takmčar je obavezan da ima dres, takmičarski broj i patike.

Zona za izmenu je prostor u kome takmičari presvlače opremu između disciplina. U zoni za izmenu takmičar je obavezan da koristi za smeštanje svoje opreme samo prostor koji je obeležen njegovim brojem. Takmičar ne sme da ometa druge takmičare u toku tranzicije. Takmičar ne sme da vozi bicikl u zoni za izmenu. Bicikl sme da vozi samo posle linije na tlu koja označava početak biciklističkog segmenta, odnosno, do oznake za kraj segmenta. Kacigu mora da stavi i da skine dok je u zoni za izmenu. U zoni izmene je dozvoljeno trčanje.

Diskvalifikacija: takmičar je diskvalifikovan ukoliko je prekšio neka od pravila, tj. kada mu sudija pokaže crveni karton.Takmičar je diskvalifikovan ukoliko je na biciklu iberundovan, tj. ako su ga vodeći takmičari obišli za čitav krug. Takmičar ima pravo da nastavi trku posle diskvalifikacije i da posle trke u propisanom roku podnese žalbu.

Oprema: što se tiče opreme ovde ćemo navesti opremu koja je obavezna za takmičenje, a to je: triatlonski dres, bicikl, kaciga i patike. Ova oprema je obavezna i bez nje se ne može učestvovati u takmičenju. Međutim, postoji mnogo više opreme koja nije obavezna, ali koja je neophodna za ozbiljnije bavljenje triatlonom. U ovu opremu se ubrajaju: sat, sprinterice za bicikl, naočare za bicikl i za plivanje, odelo za plivanje, pulsmetar, biciklistički dres, itd.

\section{Triatlon kod nas}

Triatlon se u našoj zemilji pojavio početkom 90-ih, mada je prvi triatlon održan 1988. godine u Kragujevcu i zvao se šumadijski. To takmičenje nije imalo formu kao današnja takmičenja i razlikovalo se i po distancama, a i po tome što discipline nisu bile povezane, već je postojala pauza među njima.

Godine 1993. održano je prvo prvenstvo države na Adi Ciganliji. Od tada se prvenstvo države održava svake godine i broj učesnika je iz godine u godinu sve veći $i$ što je važnije rezultati su sve bolji. 1999. godine održan je prvi kup Jugoslavije u triatlonu.

Svih ovih godina naši takmičari su napredovali $\mathrm{u}$ pogledu rezultata, tako da su postignuti uspesi na međunarodnom planu. $\mathrm{Na}$ prvenstvu Balkana 2000. godine Jugoslavija je dobila prvaka Balkana u muškoj i ženskoj konkurenciji. To su Svetlana Brkić i Nenad Sudarov.

Danas Srpska triatlonska unija pravi planove za razvoj ovoga sporta kroz intenzivniji rad sa mlađim kategorijama i pripremu naših najboljih takmičara, kako bi se kvalifikovali za naredne Olimpijske igre.

\section{Plivanje u triatlonu}

Plivački treninzi za triatlonce: plivanje je jedan od bazičnih monocikličnih sportova koji ima jednu otežavajuću okolnost, a to je okruženje 
u kome se izvodi - voda. Kako se kretati kroz vodu, tj. okruženje koje nije svojstveno čoveku, kao jednom sofisticiranom organizmu prilagođenom za život i kretanje kopnom? Odgovor na ovo pitanje se postavlja kroz čitavu epohu, odnosno, kroz jedan vremenski interval kod kojeg je čovek u ranim počecima plivao iz puke životne potrebe, npr. preživljavanja ili savladavanja jedne fizičko-geografske prepreke, pa do današnjih dana u kojima je plivanje dostiglo nivo da se gledajući pojedine svetske aktere takmičarskog plivanja pitamo - gde je kraj napretku?

Takmičarsko plivanje danas za sobom nosi jednu posebnu dimenziju i osigurava svim takmičarima optimalno jednake uslove $u$ plivačkim borilištima, tj. bazenima, koji su jasno definisani svojim standardizovanim parametrima, npr. temperatura vode trebalo bi da bude od $25^{\circ} \mathrm{C}$ $-28^{\circ} \mathrm{C}$, visina zastavica može biti $1,8-2,5 \mathrm{~m}$ iznad površine vode, itd. Pri ovakvoj standardizaciji koja je prisutna svugde u svetu, vodilo se i računa o stavkama koje bi u najboljoj mogućoj meri pomogle plivaču u orijentaciji za vreme jedne plivačke trke, koja zahteva izuzetnu tehničku preciznost izvođenja pokreta i maksimalni mogući napor. Naime, linije koje se nalaze na dnu bazena upravo su jedan od faktora koji omogućavaju plivaču da se uspešno orijentiše, ne menja pravac kretanja, pravovremeno ulazi i izlazi u okret ili cilj, te zadrži položaj tela koji će mu omogućiti najbolju tehničku efikasnost. Upravo iz svega ovog navedenog, možemo zaključiti da su u takmičarskom plivanju koje se odvija u bazenima (koji su na više načina standardizovani), orijentacija i snalaženje u vodi podređeni samom plivaču i njegovoj tehničkoj efikasnosti plivanja, kako bi postigao željeni rezultat.

Ovakav način plivanja ("vaterpolo plivanje") javlja se u triatlonu i plivačkom maratonu upravo iz razloga, jer je potrebno u velikoj gužvi i smanjenoj vidljivosti vizirati ostale plivače, signalne bove, cilj i sl. Stoga prilikom provođenja trenažnih procesa, nije na odmet simulirati ovakve situacije plivajući određene deonice (npr. 10x25m sa odgovarajućim odmorom), uzdignutom glavom, te na taj način jačati muskulaturu vrata i ramenog pojasa, a ujedno i omogućuje percipiranje koliko nam telo, naročito noge, tonu prilikom ovakvog načina plivanja. Ovakav način plivanja, ukoliko uključimo i rad nogu, tj. ako nastojimo rad nogu približiti površini, može se i upotrebiti ukoliko želimo smanjiti bočne otklone tela koji su posledica nepravilnog aktivnog i pasivnog dela zaveslaja. Međutim, što učiniti kada se vaše plivanje ne odvija u ovako optimalnim uslovima, npr. daljinsko plivanje na otvorenim vodama ili plivanje, kao jedan od segmenata triatlonske trke. U tom slučaju javlja nam se problem kako se orijentisati, pravolinijsko se kretati kroz vodu, ne krivudati i pri tome ne narušiti idealnu tehniku koju plivači koriste u bazenima. Gledajući start triatlonske trke ili plivačkog maratona možemo uočiti kako se sportisti ponašaju poput vatrepolista koji imaju "kontru", te plivaju uzdignute glave vizirajući gde je lopta ili protivnički igrač.

Kada se plivač ili triatlonac iz velikog broja plivača izdvoji i nastavi svoju trku, prema svojim mogućnostima, on nažalost nije rešio problem svoje orijentacije $i$ ne može se $u$ potpunosti posvetiti načinu takmičarskog plivanja $u$ bazenima. Plivač koji se nastoji orijentisati $u$ odnosu na obalnu liniju, postavljene bove ili druge objekte, takođe, ih mora vizirati umerenim podizanjem glave ili pogleda, koji opet narušavaju tehniku plivanja. Da bi se plivač naviknuo na ovakav način plivanja, potrebno je tokom treniranja u bazenu simulirati situacije viziranja (npr. postaviti određene predmete uz ivice bazena, po mogućnosti u svim mogućim smerovima, koje je potrebno $u$ vizirati određen broj puta $u$ poslednjoj deonici koju je potrebno preplivati $-\mathrm{u}$ $200 \mathrm{~m}$ kraul tehnikom, 10 puta vizirati određen predmet koji se nalazi u blizini bazena).

Još jedna stavka koju triatlonac ili plivač dugoprugaš na otvorenim vodama ne koristi jest okret, tj. odgurivanje od zida bazena, pa nije na odmet od ivice bazena postaviti markaciju oko koje će se sportista okretati pri tome simulirajući, npr. okret oko bove (plutače).

Pronaći način kojim se najbolje koncentrišemo na sebe i svoje mogućnosti, nije jednostavno, ali ukoliko tokom letnjih meseci raspolažete sa odrđenim pogodnim uslovima, tj. ako živite uz neku vodenu površinu bilo to more, jezero i sl, evo jednog načina kako barem u maloj meri stimulisati svoje perceptivne sposobnosti. Npr. postavite neku fiksnu bovu ili plutaču nedaleko od obale (cca $15-20 \mathrm{~m}$ ), duboko se koncentrišite te zatvorenih očiju pokušajte doplivati do iste. Vodite računa da plutača bude načinjena od materijala koji vam ne može naneti povrede prilikom udara $\mathrm{u}$ nju, a ujedno ste $\mathrm{u}$ mogućnosti menjati udaljenost, broj plutača, mesto starta izvođenja vežbe. Ovu metodu poželjno je praktikovati u grupi, te na taj način ukazati jedan drugome na greške.

Znamo da plivanje i triatlon (ne računajući štafetni segment) pripadaju individualnim sportovima kod kojih se pojedinci trkaju sa vremenom, međutim, poznavanje mogućnosti kolega sportista može nam koristit na način da 
plivamo u draftu. Korištenje draftinga možemo porediti sa npr. zavetrinom koja se koristi kod biciklizma ili trčanja. Plivajuči iza ili $u$ neposrednoj bočnoj blizini neke osobe, određenu deonicu savladavamo uz manje otpore od sportiste ispred kojeg se nalazimo, pa pri tome imamo manji energetski utrošak. Ovakav način plivanja, jasno, ne zavisi isključivo od nas. Osoba čiju propulziju koristimo, može menjati tempo plivanja, odmicati se od nas i na taj način ovaj faktor učiniti neupotrebljivim. Potrebno je stoga u plivačke treninge uključiti i ovaj način plivanja, kako bi se plivač naučio optimalnom položaju u odnosu na plivača do sebe.

Vidimo da je plivanje na otvorenim vodama specifično po mnogočemu, pa se neretko događa da sporiji plivač, naviknut plivanju u otvorenim vodama, završi plivački segment triatlona brže od plivača koji je brži na bazenu. Bitno je stoga koristiti specifične vežbe plivanja koje će sigurno osigurati bolju poziciju triatloncu za nastavak triatlona kroz biciklistički segment trke, a tako i ukupni plasman trkača.

\section{Zaključak}

Plivanje u triatlonu je vrlo važan segment, jer je plivanje prva disciplina, odnosno, disciplina kojom se otvara trka i ukoliko se trka sporo započne kasnije je vrlo teško uhvatiti pravi ritam i sustići vodeće takmičare u ostala dva segmenta (biciklu i trčanju).

Plivanje je tehnički jedna od najzahtevnijih disciplina u savremenom sportu. Razlog tome je što se telo kreće u vodi, gde ima poptunu slobodu pokreta svih delova tela i zbog toga što je potreban visok nivo koordinacije i motoričke razvijenosti kako bi se pokreti realizovali pravilno i efikasno, a koordinacija i motoričke sposobnosti se razvijaju kontinuiranim treningom $u$ periodu koji se broji godinama. 


\section{Literatura}

1. Friel, J. (1998). The Triathletes Training Bible. Colorado, USA: Velo press Boulder.

2. Counsilman, J.E. (1978). Nauka o plivanju. Beograd: Sportska knjiga.

3. http:/www.triatlon.org.rs; preuzeto:28.04.2016.

4. http:/www.triatlon.hr; preuzeto:28.04.2016. 